\title{
Systematic Review of the Epidemiology of Urinary Incontinence and Detrusor Overactivity among Patients with Neurogenic Overactive Bladder
}

\author{
Alain Ruffion $^{\mathrm{a}}$ David Castro-Diaz ${ }^{\mathrm{b}}$ Hetal Patel $^{\mathrm{c}}$ Kristin Khalaf $^{\mathrm{d}}$ \\ Ahunna Onyenwenyi $^{d}$ Denise Globe ${ }^{d}$ Corinne LeReun ${ }^{\text {e }}$ Mamuka Teneishvilif \\ Meredith Edwards ${ }^{f}$ \\ a Service Urologie, Centre Hospitalier Lyon Sud, Pierre-Bénite, France; ${ }^{b}$ Department of Urology, \\ Hospital Universitario de Canarias, Santa Cruz de Tenerife, Spain; ' Allergan EAME, Marlow, UK; \\ dAllergan Inc., Irvine, Calif., USA; Independent Biostatistician, Carrigaline, Ireland; fPRMA Consulting Ltd., Fleet, UK
}

\section{Key Words}

Neurogenic overactive bladder · Neurological bladder dysfunction - Urinary symptoms - Detrusor overactivity . Urinary incontinence $\cdot$ Epidemiology $\cdot$ Systematic review

\begin{abstract}
Background: The prevalence and incidence of neurogenic overactive bladder (nOAB) are poorly defined. This systematic literature review identified $\mathrm{nOAB}$ epidemiological data and estimated the incidence and prevalence of urinary incontinence (UI) and detrusor overactivity (DO) in patients with multiple sclerosis (MS), spinal cord injury (SCI), Parkinson's disease (PD), stroke and spina bifida. An initial search of MEDLINE, Embase, PubMed, and the Cochrane library was supplemented by an internet search for grey literature and manual searching of the bibliographies of retrieved articles. Additional study selection identified comparable studies for statistical analysis. A descriptive statistical analysis, singlearm meta-analysis and stratified analysis were conducted using predefined criteria. Summary: Initial selection identified 189 articles containing prevalence data. Secondary selection
\end{abstract}

\section{KARGER}

() 2013 S. Karger AG, Base

0251-5350/13/0414-0146\$38.00/0

E-Mail karger@karger.com

www.karger.com/ned for statistical analysis identified 39 and 52 articles with prevalence of UI and DO, respectively. Random-effect meta-analysis found the prevalence of UI was $50.9 \%$ in patients with MS, $52.3 \%$ with SCl, $33.1 \%$ with PD and $23.6 \%$ with stroke. Spina bifida was excluded due to insufficient data. The prevalence of DO may be biased and artificially elevated because it can only be measured with urodynamic investigations. Key Messages: A substantial proportion of patients with neurological conditions develop UI that may be attributable to nOAB.

๑) 2013 S. Karger AG, Basel

\section{Introduction}

Overactive bladder syndrome $(\mathrm{OAB})$, also known as urge syndrome or urgency-frequency syndrome, is characterized by urgency (with or without urgency urinary incontinence, UI), frequency and nocturia [1]. Patients who suffer from symptoms of $\mathrm{OAB}$, where the cause is neurogenic, are often referred to as having neurogenic $\mathrm{OAB}$ (nOAB). The symptoms of OAB usually stem from 
overactivity of the detrusor muscle of the bladder (detrusor overactivity, DO) but may also be caused by other forms of urethrovesical dysfunction [1]. Where the cause of $\mathrm{DO}$ is neurogenic, the condition is known as neurogenic $\mathrm{DO}(\mathrm{nDO})[1,2]$. nOAB is most commonly seen in patients with multiple sclerosis (MS), spinal cord injury (SCI), Parkinson's disease (PD), cerebrovascular accident/stroke and spina bifida [3-7]. In the majority of cases in the literature, UI among patients with underlying neurological conditions was found to be associated with $\mathrm{nOAB}$ and attributable to $\mathrm{DO}[8,9]$.

The clinical presentation, symptoms and course of $\mathrm{nOAB}$ vary depending on the nature of the underlying neurological condition. The diagnosis is made based on the history, examination and urodynamic assessment [10].

A range of terms are used in published literature to describe bladder dysfunction caused by neurological disorders. The most common term used is 'neurogenic bladder,' which describes bladder dysfunction due to neurological dysfunction which may be caused by trauma, disease or injury [11]. Neurogenic bladder is a nonspecific term that may describe conditions ranging from areflexic noncontractile bladder to DO. The range of terms used causes difficulties in evaluating the literature to assess the prevalence and incidence of $\mathrm{nOAB}$ [12].

In the absence of any systematic reviews of the epidemiology of this condition, a systematic literature review was undertaken to estimate the incidence and prevalence of UI and DO in patients with 5 neurological conditions: MS, SCI, PD, stroke and spina bifida. These 5 conditions were selected as being conditions in which bladder dysfunction is well documented.

\section{Methods}

\section{Search Strategy}

The PICOS (population, interventions, comparisons, outcomes and study designs) Systematic Reviews [13] elements were as follows: population, patients with $\mathrm{nOAB}$ or with conditions considered to be alternate terms for $\mathrm{nOAB}$ (online suppl. table A; for all online suppl. material, see www.karger.com/doi/10.1159/000353274; alternative terms were considered because of the wide variation in terminology used for neurogenic bladder disorders), UI and/or DO associated with either MS, SCI, PD, stroke or spina bifida, and outcomes of prevalence or incidence data. The search was divorced from interventions, comparisons and study design. Relevant papers were identified through electronic searches of MEDLINE, Embase, PubMed and the Cochrane library. The searches were performed on June 25, 2010 and were not limited initially by date or language. In addition, an internet search was undertaken for grey literature, and relevant articles were searched manually for further references.

\section{Selection Criteria}

Citations/abstracts of identified studies were reviewed and assessed for relevance. Full paper copies of studies considered to be relevant were reassessed for inclusion against predefined criteria. This systematic literature review was intended to be exhaustive; therefore, various types of studies were initially included (e.g. studies assessing prognostic factors or quality of life) in addition to population-based epidemiological studies. This study selection based on the predefined criteria has been termed 'study selection 1 ' and the criteria for selection are listed in table 1 .

An initial review of the data from the citations identified in study selection 1 yielded a wide range of point estimates within the data because of the significant heterogeneity of the patient populations across the studies. To produce a more accurate estimate of the prevalence of UI and DO, a second study selection was performed (termed 'study selection 2') in order to identify the most comparable studies for statistical analysis. Inclusion/exclusion criteria used for study selection 2 are also listed in table 1 .

Two independent researchers performed all stages of study selection. Any disagreements between reviewers were resolved by discussion until consensus was reached.

\section{Data Collection and Analysis}

Two researchers extracted incidence and prevalence data from included articles after study selection 1 into a data extraction table according to a predefined set of parameters. Incidence was defined as the number of new cases of $\mathrm{nOAB}$ or equivalent indication within each of the patient populations, with the neurological conditions of interest occurring during a specific time. Prevalence was defined as the total number of cases of $\mathrm{nOAB}$ or equivalent indication within the general patient population with each neurological condition of interest at a certain time.

Following study selection 2, a descriptive statistical analysis was conducted, followed by single-arm meta-analysis and stratified analysis using predefined criteria. The outcomes of interest in this analysis were the rates of UI and DO in patients with each of the conditions of interest (MS, SCI, PD and stroke). Results for spina bifida were not included in the statistical analysis because insufficient data were found. All analyses were performed in Stata SE version 8.2. (Stata Corp LP, College Station, Tex., USA).

\section{UI and DO Meta-Analyses}

The rates of DO and UI and their precisions in each study were calculated. These were then combined to produce a pooled estimate of the rate of DO and UI in patients with each neurological disease of interest. Pooling was done using both fixed-effect and random-effect models. The fixed-effect model was run using the inverse variance method, and the random-effect model was run using the DerSimonian and Laird methods [14]; the estimate of heterogeneity was taken from the inverse variance model. Heterogeneity was assessed using Cochran's Q test and the $\mathrm{I}^{2}$ statistics $[15$, 16].

For each outcome, additional random-effect models were run within prespecified subgroups of interest, which included year of publication, geographical location, sample size, urinary symptoms assessment method, use of urinary symptoms as criteria for study inclusion, and study type as stratification factors (online suppl. table B). 
Table 1. Inclusion and exclusion criteria: study selection rounds 1 and 2

\begin{tabular}{|c|c|c|}
\hline $\begin{array}{l}\text { Study } \\
\text { selection } 1\end{array}$ & 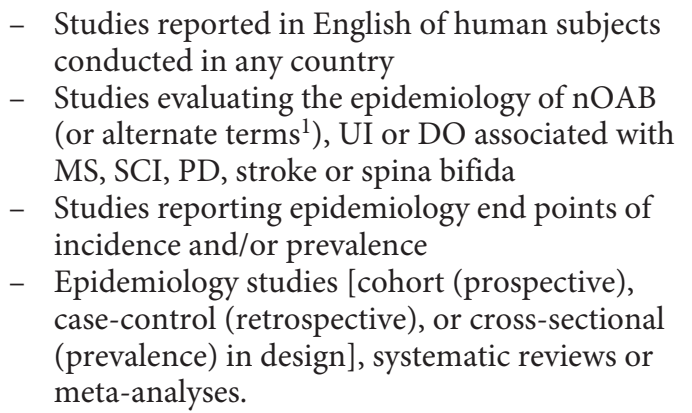 & $\begin{array}{l}\text { - In vitro or other preclinical studies } \\
\text { - Editorials, letters, case reports, commentaries, } \\
\text { interview-based market research, legal cases, newspaper } \\
\text { articles or patient education materials } \\
\text { - Studies reporting epidemiology data for nOAB (or alternate } \\
\text { terms), UI or DO associated with conditions other than } \\
\text { the neurological conditions of interest } \\
\text { - Studies assessing disease management strategies or } \\
\text { treatments as the primary aim or end point }\end{array}$ \\
\hline $\begin{array}{l}\text { Study } \\
\text { selection } 2\end{array}$ & 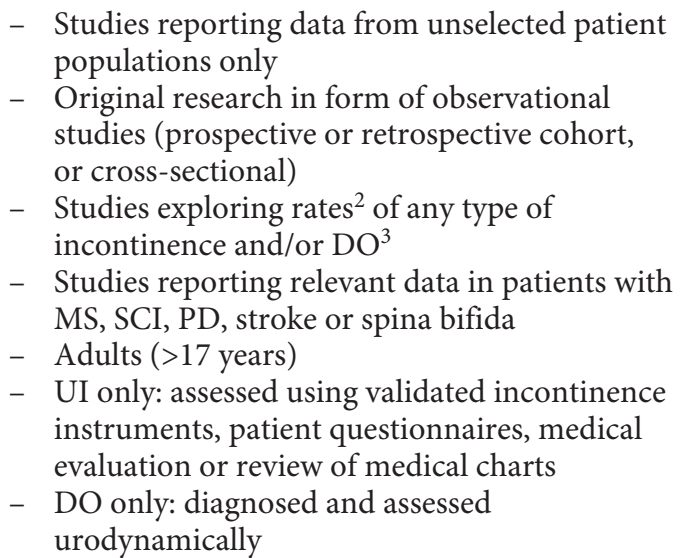 & $\begin{array}{l}\text { - Studies reporting data from selected patient populations, } \\
\text { i.e. data from: } \\
\text { - Disease subgroups } \\
\text { - Disease severity subgroups } \\
\text { - Subgroup of patients experiencing a particular symptom } \\
\text { - Patients who had undergone a particular treatment or } \\
\text { management strategy } \\
\text { - Patients reviewed in only } 1 \text { medical department } \\
\text { - Studies including patients specifically stated to have } \\
\text { surgically altered bladder, prostate enlargement or } \\
\text { preexisting history of any kind of urinary symptoms } \\
\text { - Studies including patients specifically stated to have SCI of } \\
\text { nontraumatic origin } \\
\text { - Stroke studies in which patients were assessed at or prior } \\
\text { to } 3 \text { months after stroke }\end{array}$ \\
\hline
\end{tabular}

\footnotetext{
${ }^{1}$ See online supplementary appendix A for a list of alternative terms.

${ }^{2}$ Outcomes had to be reported as the number of patients who had UI and/or DO as a fraction of the total number of patients with the neurological condition assessed.

${ }^{3}$ Also termed detrusor hyperplasia or detrusor hyperactivity in older literature.
}

\section{Results}

\section{Study Selection}

An overview of the study selection process and results are summarized in the PRISMA (Preferred Reporting Items for Systematic Reviews and Meta-Analyses) flow chart in figure 1. A total of 2,742 articles were identified from the electronic database search during study selection 1, of which 186 contained epidemiology data. Analysis and comparison of the epidemiology data identified through study selection 1 proved challenging because of the wide range of terminology used to describe nOAB. Several studies used a variety of terms such as neurogenic bladder, neuropathic bladder and bladder dysfunction, while other studies considered specific clinical conditions such as detrusor hyperreflexia or specific symptoms such as incontinence or urgency. In addition, it was difficult to compare epidemiological data between studies because of the different baseline characteristics of the patient populations such as different disease stages and severity. All of these factors contributed to the heterogeneity of the results of this systematic review. The ranges of prevalence estimates were wide and therefore inconclusive. To address this, a statistical approach was adopted requiring a second study selection to identify suitable data for the statistical analysis.

To perform the analysis on the existing data, additional study selection (study selection 2) was performed to identify studies that were closest to the general patient population and comparable within each neurological condition of interest. Using the criteria for study selection 2 listed in table 1 to assess the 186 studies in- 


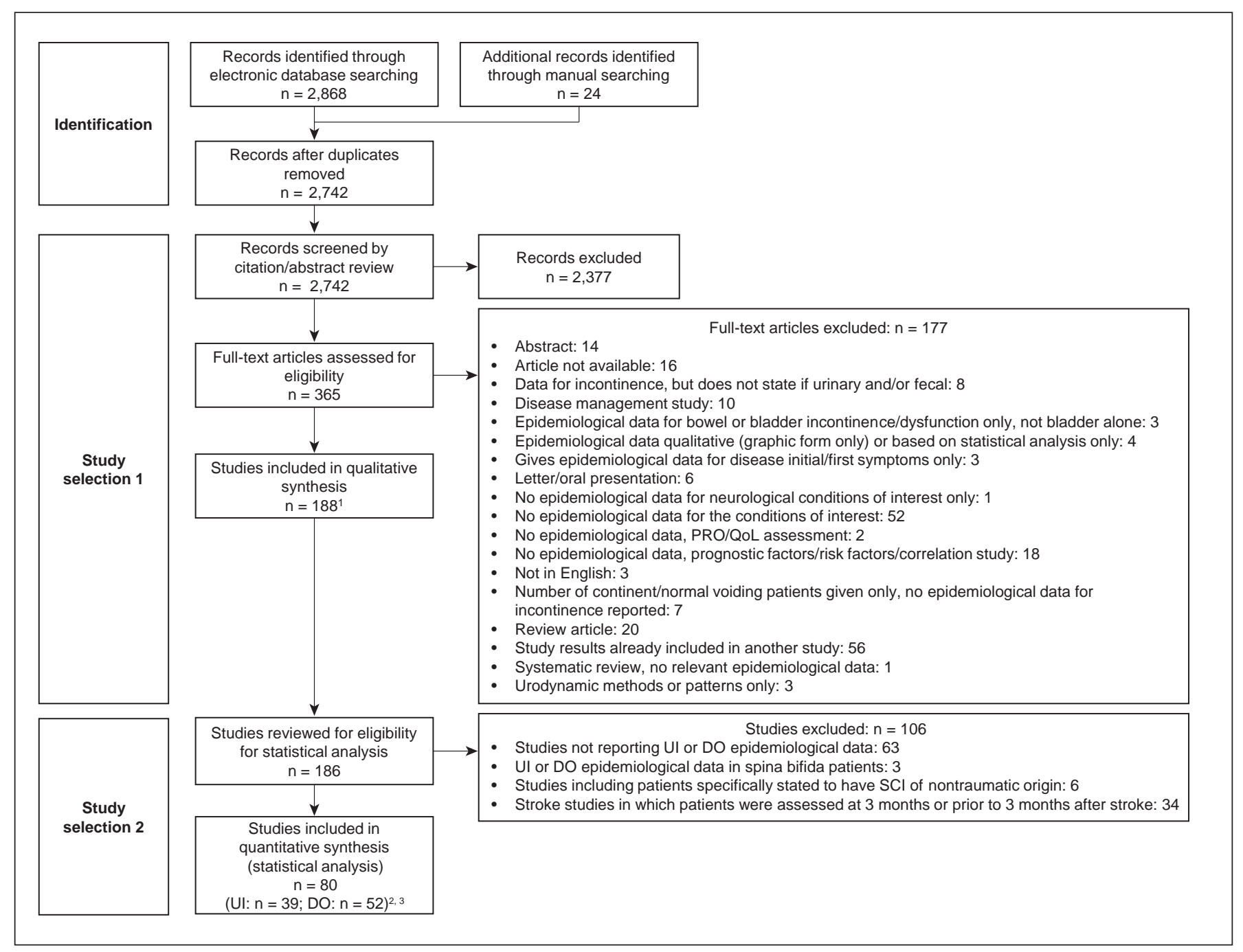

Fig. 1. PRISMA flow chart. PRO = Patient-reported outcomes; QoL = quality of life. ${ }^{1} 186$ epidemiological studies and 2 systematic reviews. ${ }^{2} 11$ studies were included for both UI and DO analysis. ${ }^{3} 2$ studies measured DO in multiple neurological populations.

cluded after study selection 1, 39 articles that reported prevalence of UI and 52 articles that reported prevalence of DO were included for statistical analysis. Details of these articles are given in online supplementary tables $\mathrm{C}$ and $\mathrm{D}$.

\section{Evidence Identified (after Study Selection 1)}

Systematic Reviews

Two systematic reviews that reported the prevalence of urological problems in patients with MS were identified $[17,18]$. Reported clinical symptoms included urgency $(32-86 \%)$, incontinence or urgency (19-80\%), fre- quency or urgency (31-85\%) and incontinence (37-72\%). Conditions that were identified urodynamically included DO (34-99\%) and detrusor underactivity (0-40\%).

\section{Qualitative Assessment of Studies}

All 186 epidemiology studies identified by the initial study selection reported prevalence data; however, none of these studies reported the incidence of urological symptoms, including $\mathrm{nOAB}$, for any of the neurological conditions of interest. The earliest study identified was published in 1973 and investigated detrusor areflexia in patients with MS [19]. 
Multiple Sclerosis. A total of 45 studies reported rates of urological symptoms in patients with MS. The prevalence of these symptoms ranged from $6.9 \%$ (defined as incontinence) in an Italian single-center study of 101 unselected patients [20] to $95 \%$ (defined as symptomatic voiding dysfunction) in a Japanese study of 32 patients referred for neurourological evaluation [21]. The prevalence of detrusor hyperreflexia ranged from $27 \%$ in a sample of consecutive patients admitted to 2 neurological centers in Italy [22] to $91 \%$ among 70 patients who underwent cystometric evaluation in a UK study [9]. The highest estimate of detrusor hyperreflexia for a relatively unselected group of patients was 70\% among 113 patients treated at a medical center in Los Angeles, Calif., USA [23].

Spinal Cord Injury. A total of 35 studies reported prevalence data for urinary symptoms in patients with SCI. Studies were divided into traumatic and nontraumatic SCI studies. The prevalence of urinary symptoms in patients with traumatic SCI ranged from $20 \%$ in a study of Medicare beneficiaries admitted to inpatient rehabilitation facilities [24] to $88.3 \%$ in a Brazilian study of 60 patients [25]. The prevalence of urinary symptoms in patients with nontraumatic SCI ranged from $5.9 \%$ at 6-month follow-up in a UK study of 25 patients with newly diagnosed non-Hodgkin's lymphoma [26] to $90 \%$ in a Pakistani study of 20 patients with a principal diagnosis of acute transverse myelitis [27]. The most frequent condition identified urodynamically was detrusor hyperreflexia. Its prevalence ranged from $11 \%$ among 70 patients referred to the Brazilian National Spinal Cord Injury Centre [28] to $85 \%$ among 42 men with thoracic lesions admitted to an SCI center in India [29].

Parkinson's Disease. The prevalence of urinary symptoms in patients with $\mathrm{PD}$, reported in 28 studies, ranged from $3 \%$ for detrusor hyperreflexia with detrusor-sphincter dyssynergia in a Japanese study of 70 patients [30] to $94 \%$ for urge incontinence in a US study of 17 women referred to a urodynamic laboratory for evaluation [31]. The prevalence of detrusor hyperreflexia alone ranged from $7.7 \%$ among a sample of 52 consecutive patients in an Italian study [22] to $93 \%$ among 30 patients referred for urodynamic evaluation for symptomatic urinary dysfunction [32].

Stroke. Data on the prevalence of urological symptoms in stroke patients were reported in 61 studies. The prevalence of such symptoms ranged from $11.1 \%$ (UI) in a Dutch study of 143 patients with first-time unilateral hemispheric stroke assessed 36-43 days after stroke onset [33] to 70\% (urgency) and 76\% (nocturia) in a Danish single-center study of 407 patients [34]. The prevalence of bladder dysfunction identified urodynamically ranged from $3 \%$ (reported as storage disorder with hypoactive detrusor) in a Turkish study of 33 patients [35] to $90 \%$ (reported as DO) in a study of 40 patients referred for urodynamic evaluation in India [4].

Spina Bifida. Data on the prevalence of urological symptoms in patients with spina bifida were identified in 25 studies. The prevalence of urological symptoms ranged from $12 \%$ (reported as incontinence at long-term followup) in an Italian study of 34 children with occult spinal dysraphism [36] to $94.9 \%$ (reported as bladder dysfunction) in 39 children with myelomeningocele in Taiwan [37]. The highest prevalence of conditions identified urodynamically was $98 \%$ (reported as neuropathic bladder) in an Italian study of 244 patients with myelomeningocele [38]. The prevalence of detrusor hyperreflexia varied from $25 \%$ in a US study of 11 patients [39] to $76 \%$ in an Italian study of 34 children with occult spinal dysraphism [36]. The prevalence of detrusor areflexia varied from $13.0 \%$ in an Italian multicenter study of 46 consecutive patients [22] to $49.5 \%$ in a Dutch study of 91 patients followed up for 7 years [40]. Owing to the significant heterogeneity across all studies within each neurological population, these results were not considered conclusive. Therefore, additional criteria were applied (study selection 2) to isolate studies that specifically measured UI and/or urodynamically confirmed DO in the general neurological populations of interest so that these data could be pooled in order to obtain a point estimate.

\section{Statistical Analysis (after Study Selection 2)}

Prevalence of UI: Meta-Analysis

The degree of heterogeneity within these data was highly significant ( $\mathrm{p}<0.001, \mathrm{I}^{2}>90 \%$ ) in all 4 neurological diseases. The random-effect model was therefore more appropriate than the fixed-effect model. The results of the meta-analysis are summarized in table 2 . Spina bifida was excluded at this stage because of insufficient data. The results of the meta-analysis of studies reporting the UI rate in MS, SCI, PD and stroke patients are shown in online supplementary tables $\mathrm{E}-\mathrm{H}$ and figures $2-5$.

\section{Prevalence of DO: Meta-Analysis}

The degree of heterogeneity within these data was highly significant ( $\left.\mathrm{p}<0.001, \mathrm{I}^{2}>75 \%\right)$ in all 4 neurological diseases. The random-effect model was therefore more appropriate than the fixed-effect model. The random-effect meta-analysis found that the prevalence of DO was $58.2 \%(50.5-65.9)$ in patients with MS, $49.7 \%$ 


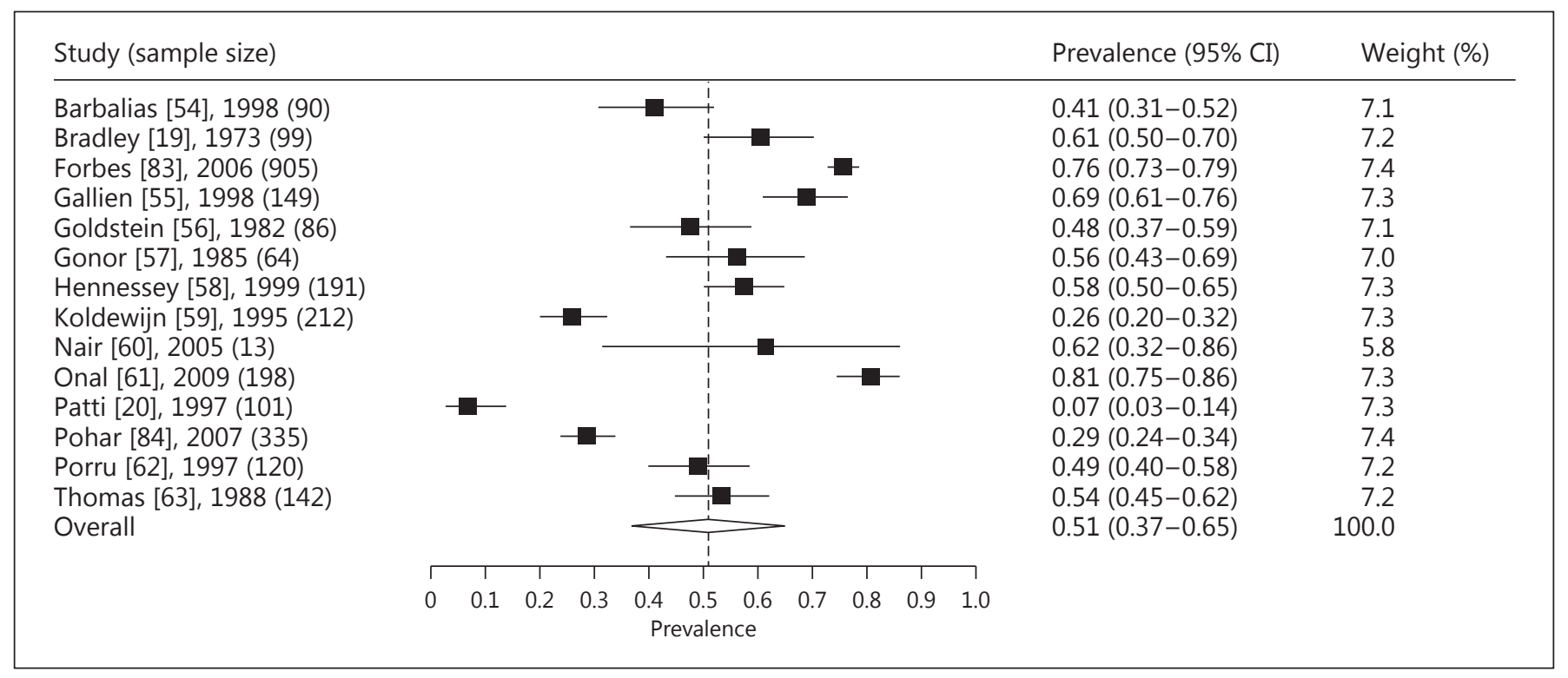

Fig. 2. Prevalence of UI in patients with MS (random-effect model) $[19,20,54-63,83,84]$. CI = Confidence interval.

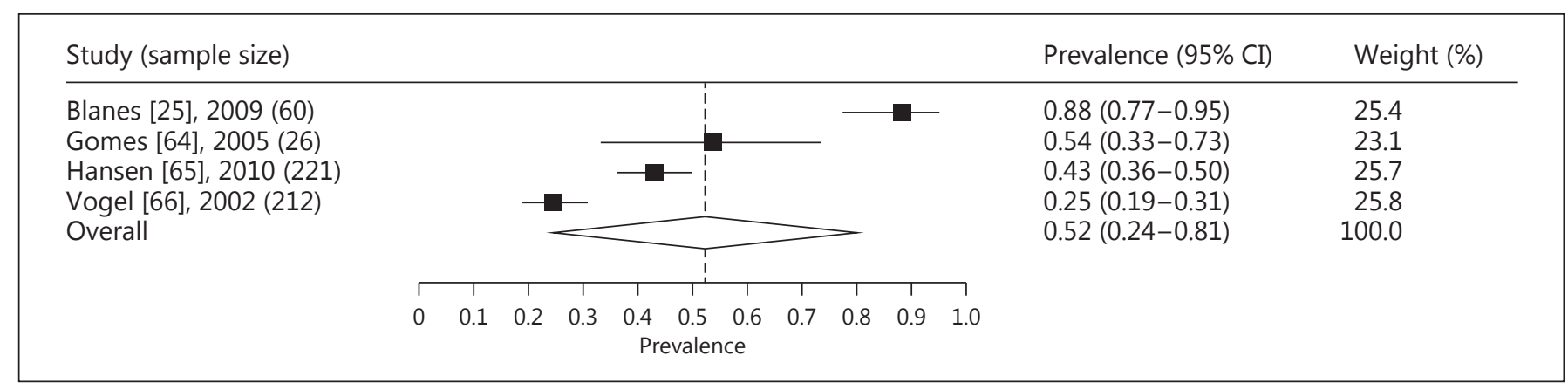

Fig. 3. Prevalence of UI in patients with SCI (random-effect model) $[25,64-66]$. CI = Confidence interval.

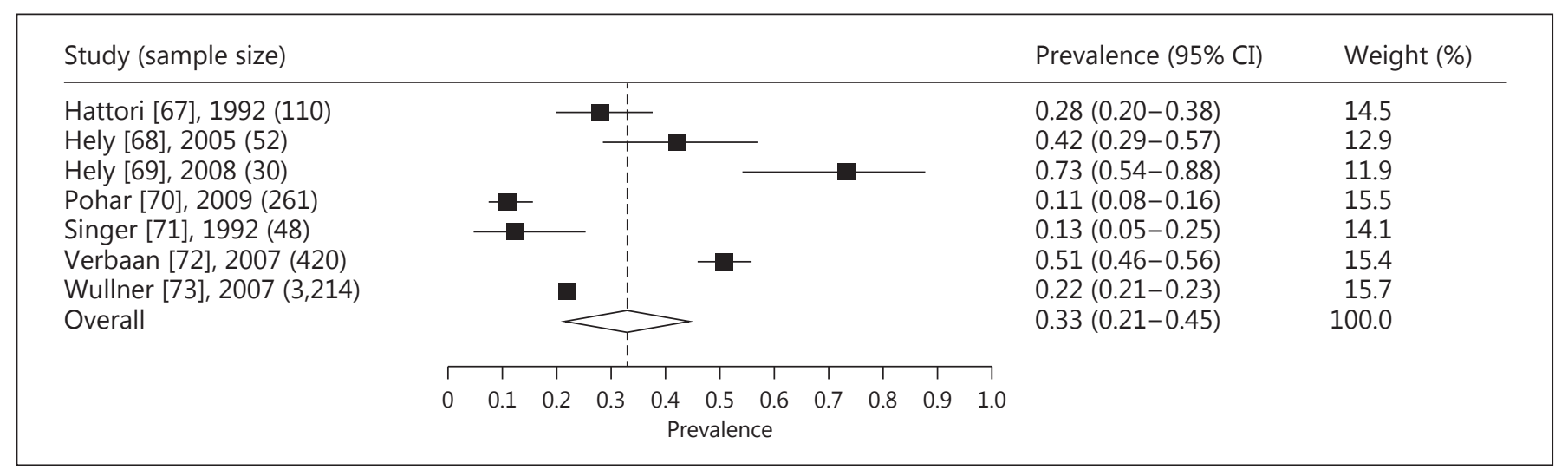

Fig. 4. Prevalence of UI in patients with PD (random-effect model) [67-73]. CI = Confidence interval. 


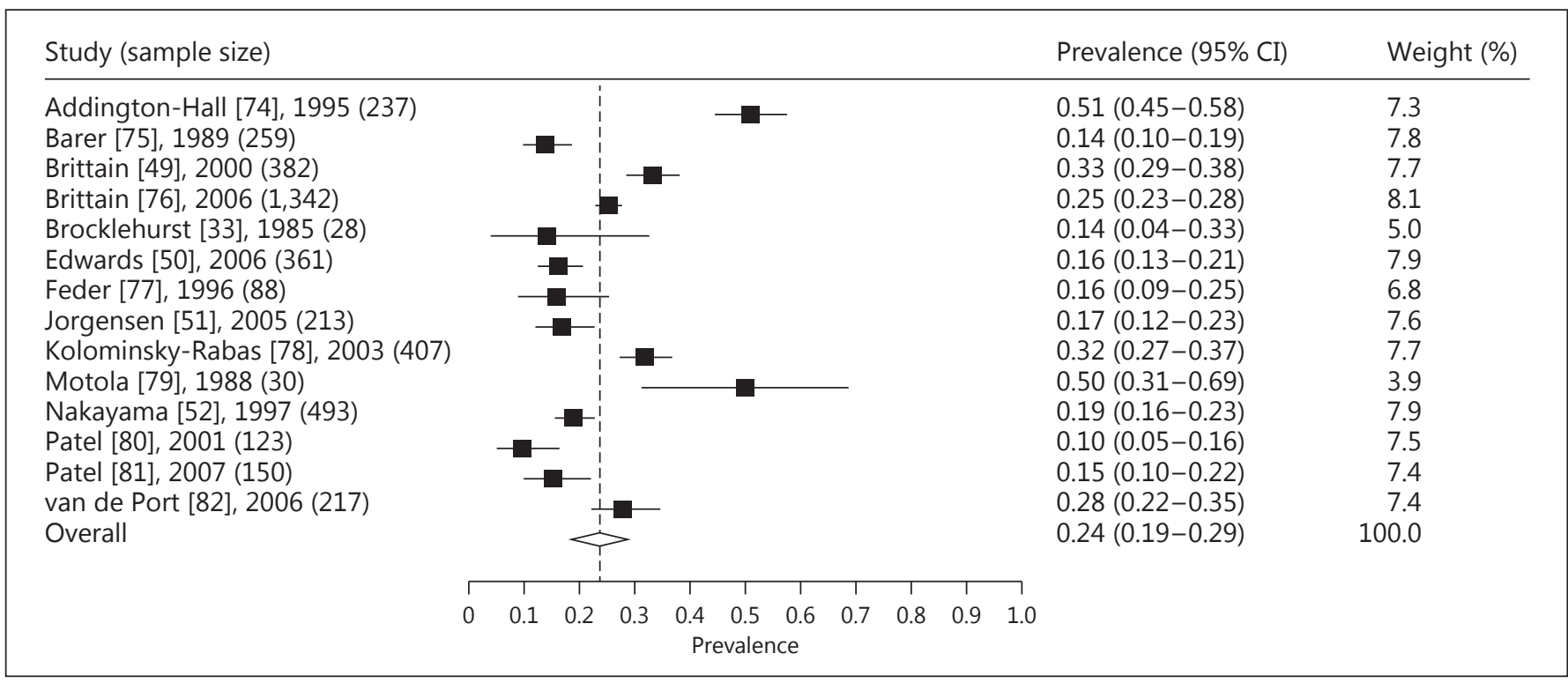

Fig. 5. Prevalence of UI in patients with stroke (random-effect model) $[33,49-52,74-82]$. CI $=$ Confidence interval.

Table 2. Results of meta-analyses for prevalence of urinary incontinence: pooled rates $(95 \% \mathrm{CI})$

\begin{tabular}{lll}
\hline $\begin{array}{l}\text { Neurological } \\
\text { disease }\end{array}$ & $\begin{array}{l}\text { Random-effect meta- } \\
\text { analysis }\end{array}$ & Heterogeneity \\
\hline MS & $0.509(0.367-0.650)$ & $\mathrm{I}^{2}=98.4 \%, \mathrm{p}<0.001$ \\
SCI & $0.523(0.238-0.807)$ & $\mathrm{I}^{2}=97.8 \%, \mathrm{p}<0.001$ \\
PD & $0.331(0.213-0.448)$ & $\mathrm{I}^{2}=97.1 \%, \mathrm{p}<0.001$ \\
Stroke & $0.236(0.185-0.288)$ & $\mathrm{I}^{2}=93.0 \%, \mathrm{p}<0.001$ \\
\hline
\end{tabular}

The table summarizes the point estimates (\%) for each neurological condition. The random-effect model takes into account that the effect size (prevalence) is similar, but not identical, across studies owing to inherent differences across studies. The $\mathrm{I}^{2}$ statistic is a measure of the inconsistency across study findings and reflects the amount of variance present across studies on a relative scale. $p$ values determined using $\chi^{2}$ test.

(37.3-62.2) in patients with SCI, 58.6\% (34.3-83.0) in patients with PD and $64.7 \%(54.2-75.3)$ in patients with stroke. Details of the meta-analysis results by neurological condition are presented in online supplementary tables I-L and online supplementary figures A-D.

For both UI and DO, the stratified analysis did not identify any significant trends. However, the number of studies included in the statistical analysis was limited and was not sufficient for the analysis to produce meaningful results. Detailed results of this analysis are not presented here.

\section{Discussion}

Analysis and comparison of the epidemiology data identified proved challenging because of the wide range of terminology used to describe nOAB. Several studies used terms such as neurogenic bladder, neuropathic bladder and bladder dysfunction, while other studies considered specific clinical conditions such as detrusor hyperreflexia or specific urinary symptoms such as incontinence or urgency. The International Continence Society terminology committee has recently provided strict definitions to be used in order to standardize the terminology used in this field; however, such naming conventions are still not being used consistently in the research when describing and studying lower urinary tract symptoms [41]. In fact, 2 large and notable MS studies that focused on urinary symptoms in this patient population $[42,43]$ were excluded during study selection 2 because, even though they measured the impact of UI symptoms on patients, they did not explicitly ask patients whether symptoms of nOAB with UI were present. Therefore, prevalence estimates could not be extracted from those studies.

In addition to inconsistency in the terminology used, comparison of epidemiological data between studies proved difficult because of the different baseline characteristics of the patient populations assessed such as underlying neurological disease stage and severity. For example, bladder dysfunction has been shown to correlate 
with disability status in patients with MS [20], voiding dysfunction has been shown to develop progressively with advancing disease in patients with $\mathrm{PD}[30]$, and the type of bladder dysfunction is significantly associated with the degree of injury in patients with SCI [44]. In addition, patients are often reluctant to discuss symptoms with their health care providers, so it is difficult to assess at what point over the course of the disease they experienced UI and/or DO [45].

This review found that the prevalence of urinary symptoms is likely to increase with the duration of PD and MS. For example, the prevalence of urinary symptoms was $39.3 \%$ at a mean disease duration of 4.9 years in a Brazilian study of 61 patients with PD [46] and $64.0 \%$ at a mean disease duration of 17.1 years in a Spanish study of 50 patients with PD [47]. In a systematic review of patients with MS, detrusor-sphincter disorders did not appear until an average of 6 years (range 5.0-9.5) after disease onset [17]. Another study of patients with MS also showed that urinary symptoms increase with disease duration [42].

While there is a clear increase in symptoms associated with $\mathrm{nOAB}$ as $\mathrm{PD}$ and MS progresses over time to more advanced stages of the disease, the trend is less clear among patients with SCI and stroke. Patients with traumatic SCI that affects bladder functioning do not necessarily experience progression in neurological deficits over time, nor are they typically able to regain neurological functioning [48]. In stroke patients, this pattern depends more on the nature and severity of the cerebrovascular insult, as well as the ability of the patients to recover from the incident. While UI may be highly prevalent in the acute phase of a stroke, symptoms may or may not resolve over time as patients regain neurological functioning [49-52]. Nevertheless, the prevalence of UI was notable in each of these patient populations, affecting over half of the patients with MS and SCI (50.9 and 52.3\%, respectively), one third of patients with PD (33.1\%), and nearly a quarter of all stroke patients at least 3 months after the acute incident $(23.6 \%)$.

Estimates for the prevalence of DO were also obtained from this study; however, these results should be interpreted with caution as DO can only be measured with urodynamic investigations. Patients are typically only referred for urodynamic workup if they are experiencing bothersome symptoms. Therefore, the DO estimates in this population are likely biased and higher than what would be expected in the population for each neurological condition. In addition, most of these studies had small patient populations ( 39 out of the 52 identified trials reporting $\mathrm{DO}$ prevalence data included less than 100 patients).
One limitation of this review is that the number of articles identified was insufficient for a reasonable stratified analysis. The meta-analysis should be interpreted with caution for this same reason. In addition, non-English language studies were excluded at the study selection stage. It also needs to be noted that no studies were identified reporting incidence data. The review was also limited by the variability in terms used to describe $\mathrm{nOAB} /$ $\mathrm{nDO}$ in the literature. Moreover, the restriction of the $\mathrm{DO}$ analysis to include only urodynamic studies caused the studied patient population to be limited to those with urinary symptoms, which led to smaller sample sizes. Finally, it is important to note that the literature search was conducted in 2010. Since this time, at least 1 study of interest has been published that was not included in this analysis to the authors' knowledge [53].

Despite these limitations, results of this review confirm that a substantial proportion of patients with underlying neurological conditions experience urinary issues. The available data, however, are insufficient to detail the exact proportion of the various urological symptoms at the various stages of the disease. This is partly the result of inconsistent terminology used to describe lower urinary tract symptoms in neurological patients. Future epidemiological studies should consistently adhere to the definitions established in 2002 by the International Continence Society. Finally, registries stratifying urinary symptoms at the various stages of diseases like MS, stroke and SCI are still needed so that clinicians know when inquiry about urinary symptoms is warranted.

\section{Conclusions}

This systematic review of the literature did not identify any data on the incidence of neurogenic bladder disorders in patients with PD, SCI, MS, stroke or spina bifida. The prevalence of urological problems varied widely, most likely reflecting the inconsistent terminology used to describe the lower urinary tract symptoms of interest. Future epidemiological studies should consistently adhere to the definitions established in 2002 by the International Continence Society. Despite these limitations, results of the meta-analysis confirm that a substantial proportion of patients with underlying neurological conditions develop $\mathrm{nDO}$ and UI. 


\section{Acknowledgments}

This study was funded by Allergan EAME. Additional editorial support was provided by PRMA Consulting Ltd., UK.

\section{Disclosure Statement}

Mamuka Teneishvili and Meredith Edwards are employees of PRMA Consulting. Hetal Patel, Kristin Khalaf, Ahunna Onyenwenyi and Denise Globe are employees of Allergan EAME. PRMA Consulting received research funding from Allergan EAME.

\section{References}

1 Abrams P, Cardozo L, Fall M, Griffiths D, Rosier P, Ulmsten U, Van Kerrebroeck P, Victor A, Wein A: The standardisation of terminology in lower urinary tract function: report from the standardisation sub-committee of the International Continence Society. Urology 2003;61:37-49.

-2 Karsenty G, Denys P, Amarenco G, De Seze M, Gamé X, Haab F, Kerdraon J, PerrouinVerbe B, Ruffion A, Saussine C, Soler JM, Schurch B, Chartier-Kastler E: Botulinum toxin A (Botox) intradetrusor injections in adults with neurogenic detrusor overactivity/ neurogenic overactive bladder: a systematic literature review. Eur Urol 2008;53:275-287.

3 Burns AS, Rivas DA, Ditunno JF: The management of neurogenic bladder and sexual dysfunction after spinal cord injury. Spine (Phila Pa 1976) 2001;26:S129-S136.

-4 Gupta A, Taly AB, Srivastava A, Thyloth M: Urodynamics post stroke in patients with urinary incontinence: is there correlation between bladder type and site of lesion? Ann Indian Acad Neurol 2009;12:104-107.

-5 Nortvedt MW, Riise T, Myhr KM, Landtblom AM, Bakke A, Nyland HI: Reduced quality of life among multiple sclerosis patients with sexual disturbance and bladder dysfunction. Mult Scler 2001;7:231-235.

-6 van Gool JD, Dik P, de Jong TP: Bladdersphincter dysfunction in myelomeningocele. Eur J Pediatr 2001;160:414-420.

7 Winge K, Fowler CJ: Bladder dysfunction in Parkinsonism: mechanisms, prevalence, symptoms, and management. Mov Disord 2006;21:737-745.

-8 Berger Y, Blaivas JG, DeLaRocha ER, Salinas JM: Urodynamic findings in Parkinson's disease. J Urol 1987;138:836-838

9 Betts CD, D’Mellow MT, Fowler CJ: Urinary symptoms and the neurological features of bladder dysfunction in multiple sclerosis. J Neurol Neurosurg Psychiatry 1993;56:245-250.

10 Chancellor MB, Anderson RU, Boone TB: Pharmacotherapy for neurogenic detrusor overactivity. Am J Phys Med Rehabil 2006;85 536-545.

11 Rackley R, Vasavada SP, Firoozi F, Ingber MS: Neurogenic bladder. eMedicine 2009. Available at: http://emedicine.medscape com/article/453539-overview\#showall. Updated November 23, 2011 (accessed September 13, 2012).

12 Kohli N, Patterson D: InterStim therapy: a contemporary approach to overactive bladder. Rev Obstet Gynecol 2009;2:18-27.
13 Centre for Reviews and Dissemination: Systematic Reviews: CRD's Guidance for Undertaking Reviews in Health Care. York, CRD, University of York, 2008. Available at: http://www.york.ac.uk/inst/crd/pdf/Systematic_Reviews.pdf (accessed September 13, 2012)

14 DerSimonian R, Laird N: Meta-analysis in clinical trials. Control Clin Trials 1986;7:177188.

15 Cochran WG: The combination of estimates from different experiments. Biometrics 1954; 10:101-129.

16 Higgins JP, Thompson SG: Quantifying heterogeneity in a meta-analysis. Stat Med 2002; 21:1539-1558.

$\checkmark 17$ de Sèze M, Ruffion A, Denys P, Joseph PA, Perrouin-Verbe $\mathrm{B}$, International Francophone Neuro-Urological Expert Study Group (GENULF): The neurogenic bladder in multiple sclerosis: review of the literature and proposal of management guidelines. Mult Scler 2007;13:915-928.

- 18 Litwiller SE, Frohman EM, Zimmern PE: Multiple sclerosis and the urologist. J Urol 1999;161:743-757.

19 Bradley WE, Logothetis JL, Timm GW: Cystometric and sphincter abnormalities in multiple sclerosis. Neurology 1973;23:1131-1139.

20 Patti F, Ventimiglia B, Failla G, Genazzani AA, Reggio A: Micturition disorders in multiple sclerosis patients: neurological, neurourodynamic and magnetic resonance findings. Eur J Neurol 1997;4:259-265.

-21 Araki I, Matsui M, Ozawa K, Takeda M, Kuno S: Relationship of bladder dysfunction to lesion site in multiple sclerosis. J Urol 2003;169: 1384-1387.

-22 Ventimiglia B, Patti F, Reggio E, Failla G, Morana C, Lopes M, Savoca F, Consoli C, Reggio A: Disorders of micturition in neurological patients. A clinical study of 786 patients. J Neurol 1998;245:173-177.

23 Sirls LT, Zimmern PE, Leach GE: Role of limited evaluation and aggressive medical management in multiple sclerosis: a review of 113 patients. J Urol 1994;151:946-950.

24 Neville C, Mallinson T, Almagor O, Fitzgerald C, Heinemann A: Impact of urinary in continence on rehabilitation outcomes in inpatient rehabilitation facilities in the United States (abstract 130). Neurourol Urodyn 2009;28:737-739.

25 Blanes L, Lourenço L, Carmagnani MI, Ferreira LM: Clinical and socio-demographic characteristics of persons with traumatic paraplegia living in Sao Paulo, Brazil. Arq Neuropsiquiatr 2009;67:388-390.
26 McDonald AC, Nicoll JA, Rampling RP: NonHodgkin's lymphoma presenting with spinal cord compression; a clinicopathological review of 25 cases. Eur J Cancer 2000;36:207-213.

-27 Kahloon AA, Arif H, Baig SM, Khawaja MR Characteristics of acute transverse myelitis at Aga Khan University Hospital, Karachi. J Pak Med Assoc 2007;57:215-218.

28 Sacomani CA, Trigo-Rocha FE, Gomes CM, Greve JA, Barros TE, Arap S: Effect of the trauma mechanism on the bladder-sphincteric behavior after spinal cord injury. Spinal Cord 2003;41:12-15.

29 Khanna R, Sandhu AS, Doddamani D: Urodynamic management of neurogenic bladder in spinal cord injury. Med J Armed Forces India 2009;65:300-304.

30 Araki I, Kuno S: Assessment of voiding dysfunction in Parkinson's disease by the international prostate symptom score. J Neurol Neurosurg Psychiatry 2000;68:429-433.

- 31 Khan Z, Starer P, Bhola A: Urinary incontinence in female Parkinson disease patients. Pitfalls of diagnosis. Urology 1989;33:486489.

-32 Pavlakis AJ, Siroky MB, Goldstein I, Krane RJ: Neurourologic findings in Parkinson's disease. J Urol 1983;129:80-83.

33 Brocklehurst JC, Andrews K, Richards B, Laycock PJ: Incidence and correlates of incontinence in stroke patients. J Am Geriatr Soc 1985;33:540-542.

34 Tibaek S, Gard G, Klarskov P, Iversen HK, Dehlendorff C, Jensen R: Are activity limitations associated with lower urinary tract symptoms in stroke patients? A cross-sectional, clinical survey. Scand J Urol Nephrol 2009; 43:383-389

35 Ersoz M, Tunc H, Akyuz M, Ozel S: Bladder storage and emptying disorder frequencies in hemorrhagic and ischemic stroke patients with bladder dysfunction. Cerebrovasc Dis 2005;20:395-399.

36 Silveri M, Capitanucci ML, Capozza N, Mosiello G, Silvano A, Gennaro MD: Occult spinal dysraphism: neurogenic voiding dysfunction and long-term urologic follow-up. Pediatr Surg Int 1997;12:148-150.

- 37 Chang CK, Wong TT, Huang BS, Chan RC Yang TF: Spinal dysraphism: a cross-sectional and retrospective multidisciplinary clinicbased study. J Chin Med Assoc 2008;71:502508

38 Torre M, Buffa P, Jasonni V, Cama A: Longterm urologic outcome in patients with caudal regression syndrome, compared with meningomyelocele and spinal cord lipoma. J Pediatr Surg 2008;43:530-533. 
39 Pérez LM, Wilbanks JT, Joseph DB, Oakes WJ: Urological outcome of patients with cervical and upper thoracic myelomeningocele. J Urol 2000;164:962-964.

40 van Gool JD, Kuijten RH, Donckerwolcke RA, Kramer PP: Detrusor-sphincter dyssynergia in children with myelomeningocele: a prospective study. Z Kinderchir 1982;37:148152.

-41 Abrams P, Cardozo L, Fall M, Griffiths D, Rosier P, Ulmsten U, van Kerrebroeck P, Victor A, Wein A: The standardisation of terminology of lower urinary tract function: report from the standardisation sub-committee of the International Continence Society. Neurourol Urodyn 2002;21:167-178.

-42 Mahajan ST, Patel PB, Marrie RA: Undertreatment of overactive bladder symptoms in patients with multiple sclerosis: an ancillary analysis of the NARCOMS Patient Registry. J Urol 2010;183:1432-1437.

-43 Marrie RA, Cutter G, Tyry T, Vollmer T, Campagnolo D: Disparities in the management of multiple sclerosis-related bladder symptoms. Neurology 2007;68:1971-1978.

-44 Weld KJ, Dmochowski RR: Association of level of injury and bladder behavior in patients with post-traumatic spinal cord injury. Urology 2000;55:490-494.

45 Ellsworth PI, Coyle PK, Esquenazi A, Andersson K-E, Burks JS, Halper J, Nitti VW, Sheremata WA, Staskin DR, Tobin PJ, Wein AJ: Consensus statement on neurogenic detrusor overactivity: multiple sclerosis and spinal cord injury. UroToday Int J 2012;5(suppl 1):art 96.

46 Campos-Sousa RN, Quagliato E, da Silva BB, de Carvalho RM Jr, Ribeiro SC, de Carvalho DF: Urinary symptoms in Parkinson's disease: prevalence and associated factors. Arq Neuropsiquiatr 2003;61:359-363.

-47 Coelho M, Marti MJ, Tolosa E, Ferreira JJ, Valldeoriola F, Rosa M, Sampaio C: Latestage Parkinson's disease: the Barcelona and Lisbon cohort. J Neurol 2010;257:1524-1532.

-48 Kirshblum S, Millis S, McKinley W, Tulsky D: Late neurologic recovery after traumatic spinal cord injury. Arch Phys Med Rehabil 2004; 85:1811-1817.

-49 Brittain KR, Perry SI, Peet SM, Shaw C, Dallosso H, Assassa RP, Williams K, Jagger C, Potter JF, Castleden CM: Prevalence and impact of urinary symptoms among community-dwelling stroke survivors. Stroke 2000;31: 886-891.

50 Edwards DF, Hahn M, Dromerick A: Poststroke urinary loss, incontinence and life satisfaction: when does post-stroke urinary loss become incontinence? Neurourol Urodyn 2006;25:39-45.

-51 Jørgensen L, Engstad T, Jacobsen BK: Self-reported urinary incontinence in noninstitutionalized long-term stroke survivors: a population-based study. Arch Phys Med Rehabil 2005;86:416-420.

52 Nakayama H, Jørgensen HS, Pedersen PM, Raaschou HO, Olsen TS: Prevalence and risk factors of incontinence after stroke. The Copenhagen Stroke Study. Stroke 1997;28:5862.
3 Manack A, Motsko SP, Haag-Molkenteller C, Dmochowski RR, Goehring EL Jr, NguyenKhoa BA, Jones JK: Epidemiology and healthcare utilization of neurogenic bladder patients in a US claims database. Neurourol Urodyn 2011;30:395-401.

54 Barbalias GA, Nikiforidis G, Liatsikos EN: Vesicourethral dysfunction associated with multiple sclerosis: clinical and urodynamic perspectives. J Urol 1998;160:106-111.

55 Gallien P, Robineau S, Nicolas B, Le Bot MP Brissot R, Verin M: Vesicourethral dysfunction and urodynamic findings in multiple sclerosis: a study of 149 cases. Arch Phys Med Rehabil 1998;79:255-257.

56 Goldstein I, Siroky MB, Sax DS, Krane RJ: Neurourologic abnormalities in multiple sclerosis. J Urol 1982;128:541-545.

57 Gonor SE, Carroll DJ, Metcalfe JB: Vesical dysfunction in multiple sclerosis. Urology 1985;25:429-431.

58 Hennessey A, Robertson NP, Swingler R, Compston DA: Urinary, faecal and sexual dysfunction in patients with multiple sclerosis. J Neurol 1999;246:1027-1032.

59 Koldewijn EL, Hommes OR, Lemmens WA, Debruyne FM, van Kerrebroeck PE: Relationship between lower urinary tract abnormalities and disease-related parameters in multiple sclerosis. J Urol 1995;154:169-173.

60 Nair KP, Taly AB, Maheshwarappa BM, Kumar J, Murali T, Rao S: Nontraumatic spinal cord lesions: a prospective study of medical complications during in-patient rehabilitation. Spinal Cord 2005;43:558-564.

61 Onal B, Siva A, Buldu I, Demirkesen O, Cetinel B: Voiding dysfunction due to multiple sclerosis: a large scale retrospective analysis. Int Braz J Urol 2009;35:326-333.

62 Porru D, Campus G, Garau A, Sorgia M, Pau AC, Spinici G, Pischedda MP, Marrosu MG, Scarpa RM, Usai E: Urinary tract dysfunction in multiple sclerosis: is there a relation with disease-related parameters? Spinal Cord 1997;35:33-36.

63 Thomas TM GM, George M, Parikshak N, Meade TW: The prevalence of urinary symptoms in patients with chronic neurological disease. Community Med 1998;10:124-129.

64 Gomes CM, Hisano M, Machado LR, Figueiredo JA, Lucon AM, Trigo-Rocha FE: Urological manifestations of chronic schistosomal myeloradiculopathy. BJU Int 2005;96: 853-856.

-65 Hansen RB, Biering-Sorensen F, Kristensen $\mathrm{JK}$ : Urinary incontinence in spinal cord injured individuals 10-45 years after injury. Spinal Cord 2010;48:27-33.

66 Vogel LC, Krajci KA, Anderson CJ: Adults with pediatric-onset spinal cord injury. Part 1. Prevalence of medical complications. J Spinal Cord Med 2002;25:106-116.

67 Hattori T, Yasuda K, Kita K, Hirayama K: Voiding dysfunction in Parkinson's disease. Jpn J Psychiatry Neurol 1992;46:181-186.

68 Hely MA, Morris JG, Reid WG, Trafficante R: Sydney Multicenter Study of Parkinson's disease: non-L-dopa-responsive problems dominate at 15 years. Mov Disord 2005;20:190199.
69 Hely MA, Reid WG, Adena MA, Halliday GM, Morris JG: The Sydney multicenter study of Parkinson's disease: the inevitability of dementia at 20 years. Mov Disord 2008;23: 837-844.

70 Pohar SL, Allyson Jones C: The burden of Parkinson disease (PD) and concomitant comorbidities. Arch Gerontol Geriatr 2009;49:317321.

71 Singer C, Weiner WJ, Sanchez-Ramos JR: Autonomic dysfunction in men with Parkinson's disease. Eur Neurol 1992;32:134-140.

72 Verbaan D, Marinus J, Visser M, van Rooden SM, Stiggelbout AM, van Hilten JJ: Patientreported autonomic symptoms in Parkinson disease. Neurology 2007;69:333-341.

73 Wullner U, Schmitz-Hubsch T, Antony G, Fimmers R, Spottke A, Oertel WH, Deuschl G, Klockgether T, Eggert K: Autonomic dysfunction in 3,414 Parkinson's disease patients enrolled in the German Network on Parkinson's disease (KNP e.V.): the effect of ageing. Eur J Neurol 2007;14:1405-1408.

74 Addington-Hall J, Lay M, Altmann D, McCarthy M: Symptom control, communication with health professionals, and hospital care of stroke patients in the last year of life as reported by surviving family, friends, and officials. Stroke 1995;26:2242-2248.

75 Barer DH: Continence after stroke: useful predictor or goal of therapy? Age Ageing 1989;18:183-191.

76 Brittain K, Perry S, Shaw C, Matthews R, Jagger $\mathrm{C}$, Potter J: Isolated urinary, fecal, and double incontinence: prevalence and degree of soiling in stroke survivors. J Am Geriatr Soc 2006;54:1915-1919.

77 Feder MRH, Motin M: Bladder control in first stroke patients after in-patient rehabilitation - relationship to age, right hemisphere damage, functional profile and neglect syndrome. Eur J Phys Rehabil Med 1996;6:106-109.

78 Kolominsky-Rabas PL, Hilz MJ, Neundoerfer B, Heuschmann PU: Impact of urinary incontinence after stroke: results from a prospective population-based stroke register. Neurourol Urodyn 2003;22:322-327.

79 Motola J, Mascarenas B, Badlani G: Cerebrovascular accidents: urodynamic and neuroanatomic findings. J Urol 1988;139:512A.

80 Patel M, Coshall C, Rudd AG, Wolfe CD: Natural history and effects on 2-year outcomes of urinary incontinence after stroke. Stroke 2001;32:122-127.

81 Patel MD, McKevitt C, Lawrence E, Rudd AG Wolfe CD: Clinical determinants of longterm quality of life after stroke. Age Ageing 2007;36:316-322.

82 van de Port IG, Kwakkel G, Schepers VP, Lindeman E: Predicting mobility outcome one year after stroke: a prospective cohort study. J Rehabil Med 2006;38:218-223.

83 Forbes A, While A, Mathes L, Griffiths P: Health problems and health-related quality of life in people with multiple sclerosis. Clin Rehabil 2006;20:67-78.

84 Pohar SL, Jones CA, Warren S, Turpin KV, Warren K: Health status and health care utilization of multiple sclerosis in Canada. Can J Neurol Sci 2007;34:167-174. 